\title{
Healing of bone defects by induced pluripotent stem cell-derived bone marrow mesenchymal stem cells seeded on hydroxyapatite- zirconia
}

\author{
Lishen Zhou, Renfu Quan, Jun Yang, Hong Xu \\ Department of Orthopedic Surgery, Xiaoshan Hospital of Traditional Chinese Medicine, Hangzhou, China \\ Contributions: (I) Conception and design: R Quan; (II) Administrative support: None; (III) Provision of study materials or patients: None; (IV) \\ Collection and assembly of data: None; (V) Data analysis and interpretation: L Zhou, H Xu, R Quan; (VI) Manuscript writing: All authors; (VII) \\ Final approval of manuscript: All authors. \\ Correspondence to: Lishen Zhou. Department of Orthopedic Surgery, Xiaoshan Hospital of Traditional Chinese Medicine, Hangzhou 311201, China. \\ Email: zhoulishen1992@163.com.
}

Background: Induced pluripotent stem cells (iPSCs) can generate bone marrow mesenchymal stem cells
(BMSCs) as seed cells for tissue-engineered bone to repair bone defects. In this study, we investigated the
effects of hydroxyapatite-zirconia $\left(\mathrm{HA} / \mathrm{ZrO}_{2}\right)$ composites combined with iPSC-derived BMSCs as a bone
substitute on repairing skull defects in rats.

Methods: Human urinary cells isolated from a healthy donor were reprogramed into iPSCs and then induced into BMSCs. Immunocytochemistry (IHC) and reverse transcription-polymerase chain reaction (RT-PCR) were used to examine the characteristics of the induced MSCs. The iPSC-derived BMSCs were cultured on $\mathrm{HA} / \mathrm{ZrO}_{2}$ composites, and cytocompatibility of the composite was analyzed by cell counting kit-8 (CCK-8) assays, RT-PCR, and scanning electron microscopy. Then, $\mathrm{HA} / \mathrm{ZrO}_{2}$ combined with iPSCderived expanded potential stem cells (EpSCs) were transplanted onto skull defects of rats. The effects of this composite on bone repair were evaluated by IHC.

Results: The results showed that MSCs induced from iPSCs displayed the phenotypes and property of normal BMSCs. After seeding on the $\mathrm{HA} / \mathrm{ZrO}_{2}$, iPSC-derived BMSCs had the ability to proliferate and differentiate into osteoblasts. After transplantation, iPSC-derived BMSCs on $\mathrm{HA} / \mathrm{ZrO}_{2}$ promoted construction of bone on rat skulls.

Conclusions: These results indicated that transplantation of a $\mathrm{HA} / \mathrm{ZrO}_{2}$ combined with iPS-derived BMSCs is feasible to reconstruct bones and may be a substantial reference for iPSC-based therapy for bone defects.

Keywords: Induced pluripotent stem cell (iPSC); bone marrow mesenchymal stem cells (BMSCs); bone regeneration; hydroxyapatite-zirconia $\left(\mathrm{HA} / \mathrm{ZrO}_{2}\right)$

Submitted Sep 06, 2021. Accepted for publication Nov 12, 2021.

doi: $10.21037 / \mathrm{atm}-21-5402$

View this article at: https://dx.doi.org/10.21037/atm-21-5402

\section{Introduction}

Bone defect is the destruction of the integrity of bone, which can usually be repaired through physiological evolution in vivo. However, large bone defects caused by severe bone trauma, osteomyelitis, bone tumors, or congenital osteopathy cannot be repaired through the physiological function of the body. Autogenous bone transplantation is often used to treat bone defects expected to not heal spontaneously. However, the source of bone used for transplantation is limited, and autologous transplantation inevitably causes secondary trauma in the donor site, while increasing pain and the risk of infection. 
The use of allogeneic bone can partly alleviate the problem of insufficient bone sources for transplantation; however, it carries the risk of disease transmission and immune rejection. Metal and ceramic bone substitutes have the advantages of high strength and wide resource, but they lack biological activity and are easily prone to aging and loosening (1). Bone tissue engineering provides a new option for bone defect treatment by implanting cultured cells into biocompatible scaffolds. Seed cells adhere to and proliferate on scaffolds, differentiate into osteoblasts, mineralize to form bone, and then fill in the bone defect.

Cells are essential for bone tissue engineering (2). At present, seed cells mainly include embryonic stem cells (ESCs), induced pluripotent stem cells (iPSCs), adult stem cells/mesenchymal stem cells (MSCs) and osteoblasts (3). Osteoblasts, as a direct source of bone regeneration, have excellent osteogenic properties; however, as terminal cells, they have limited proliferation ability and insufficient source, which restricts their application as seed cells. The ESCs are omnipotent stem cells with super self-renewal and differentiation ability, but ethical problems limit their clinical application. To date, MSCs are the most widely studied cells and have been used in clinic. They can be obtained from bone marrow, umbilical cord blood, fat, placenta, endothelium, and other tissues. They have strong proliferation and differentiation ability and low immunogenicity.

However, the acquisition of MSCs, such as BMSCs, requires bone marrow extraction, which often causes great pain to patients. The number of BMSCs is very small, with only one BMSC per 100,000 nucleated cells in bone marrow $(4,5)$. Contrastingly, iPSCs are derived from reprogramming of somatic cells and have strong self-renewal, proliferation, and differentiation capabilities similar to ESCs. There are no ethical issues, but undifferentiated iPSCs are tumorigenic, which limits their clinical application (6). Differentiation of iPSCs into mesenchymal stem cell-like cells (iPS-MSCs) results in similar biological properties and functions as MSCs, but there is no influence of MSCs acquisition and individual differences, nor ethical issues of ESCs. As a new type of seed cell, iPS-MSCs have abundant sources, strong differentiation ability, and good consistency. By detecting and comparing the telomerase activity of iPSMSCs and MSCs, it was found that the telomerase activity of iPS-MSCs was 10 times higher than that of MSCs, which indicated that iPS-MSCs had stronger proliferation ability. More importantly, oncogenic genes OCT4, TRA-1-81, and TRA-1-60 were not expressed in iPS-MSCs, and no tumors were found in tumorigenicity testing of iPS-MSCs, which further demonstrated the safety of iPS-MSCs.

In recent years, iPS-MSCs have provided breakthrough progress in the treatment of osteonecrosis and bone defects $(7,8)$. However, there are few reports on the transplantation of IPS MSCs into $\mathrm{HA} / \mathrm{ZrO}_{2}$ as tissue-engineered bone materials. In our previous studies, gradient composites of zirconia and hydroxyapatite $\left(\mathrm{HA} / \mathrm{ZrO}_{2}\right)$ have been shown to have a three-dimensional (3D) porous structure with good biocompatibility. Moreover, when combined with BMSCs, $\mathrm{HA} / \mathrm{ZrO}_{2}$ showed a good therapeutic effect on Beagle canine bone defects.

Here, we differentiated urine cell-derived iPSCs into BMSCs, and cultured these cells on a $\mathrm{HA} / \mathrm{ZrO}_{2}$ scaffold to form tissue-engineered bone that was then transplanted into the skull defect of rats. The effects of iPSC-derived MSCs on bone regeneration were then analyzed, and the feasibility of using iPSC-derived MSCs as seed cells to construct bone substitutes to repair bone defects were also assessed.

We present the following article in accordance with the ARRIVE reporting checklist (available at https://dx.doi. org/10.21037/atm-21-5402).

\section{Methods}

\section{Generation and analysis of iPS-MSCs}

Urine cells (UCs) were collected from a 24-year-old healthy male volunteer (after he had provided informed consent), and reprogrammed into iPSCs by introducing 4 exogenous transcription factors (OCT4, SOX2, C-MYC, KLF4) into human UCs using a retrovirus-mediated infection system. Briefly, we used calcium phosphate transfection to introduce 4 plasmids (OCT4, SOX2, C-MYC, and KLF4) into $393 \mathrm{~T}$ cells, then respectively collected viral fluids for $48 \mathrm{~h}$ and $72 \mathrm{~h}$. The UCs were infected twice with the addition of polybrene containing a final concentration of $8 \mu \mathrm{g} / \mathrm{mL}$ and changed to UC culture medium $12 \mathrm{~h}$ later. After 4-5 days of infection, the nucleocytoplasmic ratio became larger, and the cells were spread onto embryonic fibroblast (MEF) feeder cells and $\left(2 \times 10^{5} / 10 \mathrm{~cm}\right.$ dish) were replaced with human (h)ESCs medium (20\% dermal fibroblast cells + knockout serum replacement (DFBs + KSR) medium). All of cultures were supplemented with $50 \mu \mathrm{g} / \mathrm{mL}$ each of vitamin $\mathrm{C}$ and $1 \mathrm{mM}$ final concentration of valproic acid (VPA) until the clonogenic cells appeared. The clonal iPSCs were collected onto 6-well plates plated with an MEF-like layer or Matrigel, cultured with mTesR1 
medium. The Culture medium was changed daily.

When iPSCs reached about $30 \%$ confluence, they were switched to MSCs induction medium including minimum essential medium a (aMEM; Sigma-Aldrich, St. Louis. MO, USA, M4526), 10\% fetal bovine serum (FBS; Gibco, Amarillo, TX, USA), 2 mm glutamine (Sigma, G7513), $100 \mu \mathrm{m}$ ascorbic acid (Wako, Richmond, VA, USA, 013-12061)1 mM sodium pyruvate (Sigma, s8636), nonessential amino acids (Gibco) and 4-(2-hydroxyethyl)-1piperazineethanesulfonic acid (HEPES; Sigma), maintained in culture for 2 weeks with fluid changed every 3-4 days. After 2 weeks, cells were passaged by digestion with pancreatin replacement medium and passaged onto gelatin $0.1 \%$ (after which no plating was required), denoted as $\mathrm{P} 1$, and passaged continuously until more homogeneous mesenchymal-like cells emerged. Afterwards, culture was switched to mesenchymal stem cell medium (5\% UltraGRO TM advanced + aMEM).

The BMSCs samples serving as controls were collected from patients with normal hip fracture at the Xiaoshan Hospital of Traditional Chinese Medicine. All procedures performed in this study involving human participants were in accordance with the Declaration of Helsinki (as revised in 2013). The study was approved by the Ethics Committee of Xiaoshan Hospital of Traditional Chinese Medicine (No. 2014396) and informed consent was taken from all the patients. Briefly, $5 \mathrm{~mL}$ of bone marrow was diluted 1:1 with phosphate-buffered saline (PBS). The bone marrow was dropped into a $50 \mathrm{~mL}$ centrifuge tube containing $10 \mathrm{~mL}$ Ficoll using a Pap pipette, $1,800 \mathrm{rpm}, 25^{\circ} \mathrm{C}$, for $18 \mathrm{~min}$ centrifugation. We then aspirated the middle flocculent layer into a new centrifuge tube with PBS dilution, washed it twice, and performed $10 \mathrm{~min}$ centrifugation at 1,000 rpm and $4{ }^{\circ} \mathrm{C}$. After the MSC medium was resuspended, it was seeded into $10 \mathrm{~cm}$ dishes and replenished to $10 \mathrm{~mL}$. After $48 \mathrm{~h}$, half of the medium was changed every 2 days, using pancreatin replacement digested for $1: 3$ passages after confluency.

The expression of OCT4, NANOG, and vimentin proteins after the iPSCs had differentiated into iPS-MSCs was evaluated by immunofluorescence, and BMSCs were used as control. The glass pieces were built into 24 well plates first, and then the cells were seeded on the climbing pieces. When the density of cells had grown appropriately, they were washed once with PBS. Cells were first fixed in 4\% paraformaldehyde (PFA) for $30 \mathrm{~min}$ at room temperature, then permeabilized in $0.2 \%$ Triton for $30 \mathrm{~min}$ at room temperature, after which they were fixed in $3 \%$ bovine serum albumin (BSA) for $2 \mathrm{~h}$ at room temperature. The liquid was aspirated and discarded, and the cells were then incubated with antibodies in $1 \%$ BSA configuration overnight in the dark at $4{ }^{\circ} \mathrm{C}$, and finally secondary antibodies were added and incubated for $1-2 \mathrm{~h}$ in the dark at room temperature. At the end of each step above, the cells were washed 3 times with PBS for $5 \mathrm{~min}$ and shaken at $30 \mathrm{rpm}$. Subsequently, they were added to a final concentration of $1 \mu \mathrm{g} / \mathrm{mL}$ 4',6-diamidino-2-phenylindole (DAPI; Sigma-Aldrich), $0.5 \mathrm{~mL}$ per well, and kept in the dark at room temperature for $5 \mathrm{~min}$. The sections were sealed and observed under a fluorescence microscope (LSM710, ZEISS, Oberkocken, Germany).

Expression of pluripotency genes OCT4, NANOG and mesoderm marker gene vimentin on iPS-MSCs was examined by RT-PCR, with iPSCs and BMSCs as controls. Total RNA was extracted from cells at different differentiation stages according to the RNA kit instructions. The RNA was reverse transcribed into complementary DNA (cDNA) according to the reverse transcription kit instructions, and then the relative quantification of messenger RNA (mRNA) expression of each gene was performed on a quantitative realtime polymerase chain reaction (qPCR) instrument according to the manufacturer's instructions. The reverse transcription (RT)-PCR results were confirmed by at least 3 independent analyses. Relative gene expression was calculated using the $2^{-\Delta \triangle C T}$ method relative to the glyceraldehyde 3-phosphate dehydrogenase (GAPDH) control. The primer sequences are given in Table 1.

Flow cytometry analysis was conducted as follows: Pancreatin substitute was used to digest and collect cells, which was washed twice with prechilled PBS, and then incubated with fitc-14, fitc-45, fitc-90, fitc-14, fitc-hla-dr, pe-34, pe-44, pe-73, PE-1, apc-19, and apc-105 antibodies (all mouse anti-human antibody, Becton, Dickinson, and Co. (BD), Franklin Lakes, NJ, USA) in the dark for $30 \mathrm{~min}$. The tubes without antibodies were set up as blank controls. After washing with PBS, cells were resuspended in buffer (no less than $1 \times 10^{4}$ cells per tube) and then processed for analysis on a Fortessa Flow Cytometer (BD, USA).

Multipotent differentiation capacity was analyzed as follows: Cells were seeded into 6 well plates until they reached about $70 \%$ confluence. Then, the medium was replaced respectively with osteogenic and adipogenic induction medium which was changed every 3 days. The differentiation lasted for 21 days. The cells were then stained by Alizarin red and oil red $\mathrm{O}$, respectively. For chondrogenic differentiation, $5 \times 10^{5}$ cells were collected by centrifugating 
Table 1 Primer sequences for RT-PCR

\begin{tabular}{lll}
\hline Gene name & Forward & Reverse \\
\hline OCT4 & CCTCACTTCACTGCACTGTA & CAGGTTTCTTTCCCTAGCT \\
GAPDH & TGAACCTCAGCTACAAACAG & TGGTGGTAGGAAGAGTAAAG \\
VIMENTIN & ATTGCCCTCAACGACCACT & ATGAGGTCCACCACCCTGT \\
Runx2 & CGGGAGAAATTGCAGGAGGA & AAGGTCAAGACGTGCCAGAG \\
Col1a1 & CTGTGGTTACTGTCATGGCG & AGGTAGCTACTTGGGGAGGA \\
ALP & AGGGCCAAGACGAAGACATC & AGATCACGTCATCGCACAAC \\
OCN & ATCAGGGACATTGACGTGATC & TTCCAGGTGTCAACGAGGTC \\
\hline
\end{tabular}

RT-PCR, reverse transcription-polymerase chain reaction.

into $15 \mathrm{~mL}$ centrifuge tubes (pellet) and adding to chondrogenic induction medium. The cell pellets were gently blown up while changing the medium every 3 days. The samples were embedded in paraffin and sectioned for identification by Alcian blue staining after 21 days.

Teratoma formation test was conducted as follows: The iPS-MSCs (P6) and iPSCs were trypsinized into singlecell suspensions and re-suspended in PBS at the density of $1 \times 10^{7}$ cells $/ \mathrm{mL}$. A total of $100 \mu \mathrm{L}$ iPS-MSCs, iPSCs suspensions, and the pure PBS were injected subcutaneously into the hind limbs of 8-week-old male nonobese diabetic/ severe combined immunodeficiency (NOD-SCID) mice (Shanghai Slac Laboratory Animal Co. Ltd, Shanghai, China), respectively. Teratoma formation was examined after transplantation for 8 weeks.

\section{Culture and osteogenic differentiation of iPS-MSCs on $\mathrm{HA} / \mathrm{ZrO}_{2}$ scaffolds}

The $\mathrm{HA} / \mathrm{ZrO}_{2}$ porous gradient composite foams ceramic materials were obtained by mechanical foam impregnation combined with gradient composite high-temperature sintering and the materials were provided by Shanghai University School of Material Science and Engineering. The sponges were pretreated with $15 \mathrm{wt} \%$ sodium hydroxide solution, then air dried sponges were immersed into the slurry with repeated soaking 3 times. The main components of the slurry, which was thoroughly stirred and mixed with distilled water, included $\mathrm{ZrO}_{2}$ powder $(65 \%$, $60 \%, 55 \%$ wt $\%$, respectively), polyvinyl alcohol (PVA, $0.5 \mathrm{wt} \%$ ), carboxymethylcellulose (CMC, $0.5 \mathrm{wt} \%$ ), silica sol (10 wt \%), ammonium polyacrylate (PAA-NH4, $0.6 \mathrm{wt} \%$ ), and octanol (0.5 wt\%). After soaking, the excess slurry was blown by nitrogen $\left(\mathrm{N}_{2}\right)$ and dried in an oven at $110{ }^{\circ} \mathrm{C}$ for $24 \mathrm{~h}$. After drying, the foam materials with slurry immersed were sintered at $1,550{ }^{\circ} \mathrm{C}$ to obtain porous $\mathrm{ZrO}_{2}$ scaffolds. Then, $\mathrm{ZrO}_{2}$ scaffolds were soaked gradually into a mixture of $30 \% \mathrm{HA} / 70 \% \mathrm{ZrO}_{2}, 50 \% \mathrm{HA} / 50 \% \mathrm{ZrO}_{2}, 100 \% \mathrm{HA}$, which had to be air dried before each soak. Finally, a porous $\mathrm{HA} / \mathrm{ZrO}_{2}$ gradient composite foam ceramic material was successfully fabricated by sintering and cooling at $1,250{ }^{\circ} \mathrm{C}$ in a furnace.

Cell adhesion: The materials were firstly sterilized using a autoclave $\left(121.3^{\circ} \mathrm{C}, 20 \mathrm{~min}\right)$ and then immersed in a-MEM which was put in a cell culture incubator for $1 \mathrm{~h}$. The iPSMSCs and BMSCs were seeded onto $\mathrm{HA} / \mathrm{ZrO}_{2}$ respectively and cultured with osteogenic differentiation medium and normal medium without inducer. After 7 days, the samples were gradually fixed with $2 \%$ glutaraldehyde solution for $4 \mathrm{~h}, 1 \%$ osmic acid solution for $1 \mathrm{~h}$, dehydrated through graded ethanol gradients $(30 \%, 50 \%, 70 \%, 80 \%, 90 \%$, $95 \%, 100 \%)$, until they reached the critical point and then sputtered gold. Finally, we photographed the samples under scanning electron microscope to observe the adhesion of iPS-MSCs and BMSCs on $\mathrm{HA} / \mathrm{ZrO}_{2}$.

For proliferation analysis, cells were seeded into a 96 well plate $\left(2 \times 10^{3}\right.$ cells/well), with 3 replicate wells per group. The CCK- 8 was added to wells at 1,4 , and 7 days postinfection $(10 \mathrm{~L} /$ well $)$ and examined $1 \mathrm{~h}$ later. The OD values were measured at $450 \mathrm{~nm}$ to estimate viable cells. The cell viabilities were expressed as relative growth rate $(\mathrm{RGR})$ determined by RGR $(\%)=[(\mathrm{OD})$ sample/OD (negative control)] $\times 100 \%$. Toxicity grade: An RGR $\geq 100 \%$ was classified as grade $0,75 \% \leq \mathrm{RGR}<100 \%$ as grade I, 
$50 \% \leq \mathrm{RGR}<75 \%$ as grade II, $25 \% \leq \mathrm{RGR}<50 \%$ as grade III, $1 \% \leq \mathrm{RGR}<15 \%$ as grade IV, and RGR $=0$ as grade $\mathrm{v}$.

For osteogenic differentiation, iPS-MSCs and BMSCs were respectively seeded at $1 \times 10^{4} / \mathrm{cm}^{2}$ on $15 \mathrm{~mm}$ diameter $\mathrm{HA} / \mathrm{ZrO}_{2}$ materials in 12 well culture plates and Alizarin red staining was performed at 7,14 , and 21 days. Cells were fixed with $90 \%$ ethanol for $10 \mathrm{~min}$ and then stained using $0.2 \%$ Alizarin red solution with a $\mathrm{pH}$ of 6.4 for $30 \mathrm{~min}$ at room temperature. After washing with double-distilled water to remove unbound dye, cells were imaged by light microscopy. The expressions of Runx2, COL1A1, ALP, and $O C N$, which were specifically related to osteogenic differentiation of iPS-MSCs and BMSCs, were determined by fluorescence qPCR in different time periods $(7,14$, and 21 days). Methods of fluorescence qPCR were as previously described. Primer design sequences are shown in Table 1.

\section{Repair of $\mathrm{HA} / \mathrm{ZrO} \mathrm{O}_{2}$ combined with iPS-MSCs on rat skull defects}

Animal experiments were performed under a project license (No. 10296) granted by the Ethics Committee of Xiaoshan Hospital of Traditional Chinese Medicine, in compliance with the hospital guidelines for the care and use of animals. A protocol was prepared before the study without registration. The animals were housed and surgically manipulated following the guidelines established by the animal ethics committee in the hospital, which gives laboratory animal care and reduces suffering. Male SD rats aged $8-10$ weeks were used in the experiments, which were purchased from the animal experimental center of Zhejiang University. Anesthesia was achieved by intraperitoneal injection of ketamine $(70 \mathrm{mg} / \mathrm{kg}$ bodyweight $)$ and xylazine $(10 \mathrm{mg} / \mathrm{kg})$, followed by local anesthesia with $2 \mathrm{~mL}$ lidocaine injected on rats' calvaria. A linear sagittal incision was made along the middle calvaria, followed by a full thickness incision to expose periosteum. A bone window of approximately $0.6 \mathrm{~cm}$ in diameter was drilled on both left and right side of the rat skull using an electric dental bur. A total of 18 numbered rats were randomly grouped by random number table. The experiments were divided into 3 groups: $\mathrm{HA} / \mathrm{ZrO}_{2}$ material alone $(\mathrm{n}=6), \mathrm{HA} / \mathrm{ZrO}_{2}$ combined with iPS-MSCs osteogenic differentiated in vitro for 7 days group (IPS-MSc $+\mathrm{HA} / \mathrm{ZrO}_{2}, \mathrm{n}=6$ ), and $\mathrm{HA} / \mathrm{ZrO}_{2}$ combined with BMSC osteogenic differentiated in vitro for 7 days group (BMSC $+\mathrm{HA} / \mathrm{ZrO}_{2}, \mathrm{n}=6$ ). All groups had material grafted on the bone window of the left side and no material grafted on the right side as blank control. Rats were housed in a constant greenhouse at $20^{\circ} \mathrm{C}$ with a $12 \mathrm{~h}$ light/dark cycle. Food and water were provided ad libitum. All the rats received an injection of immunosuppressant cyclosporine A (30 mg/kg bodyweight) every day.

At 12 weeks after surgery, all rats had survived well and were included in the outcome study, which involved euthanasia by ether overdose anesthesia. The skull tissues were scanned using animal micro-computed tomography (CT) (SkyScan Bruker Belgium) and MicroView ABA software (GE Healthcare, Chicago, IL, USA) for bone mass analysis.

\section{Statistical analysis}

Statistical analyses were performed using SPSS 22.0 (IBM Corp., Armonk, NY, USA). All data were expressed as the mean value \pm standard deviation (SD). Statistical significance was analyzed using one way analyses of variance (ANOVA), followed by post hoc least significant difference (LSD) tests. A confidence level of 95\% (95\% CI) was considered significant.

\section{Results}

\section{Generation and characterization of iPS-MSCs}

Differentiation was induced by serial passaging (Figure 1). After several passages, the cells changed from the original clonal mass shaped iPSCs (Figure 1A) into fibroblast-like iPS-MSCs (Figure 1E), which was morphologically similar to BMSCs (Figure 11). The results of immunofluorescence analysis showed that the positive expressions of pluripotency genes OCT4 and NANOG in iPSCs (Figure $1 B, 1 C$ ) were barely detected in iPS-MSCs (Figure $1 F, 1 G$ ) and BMSCs (Figure $1 \mathcal{F}, 1 \mathrm{~K}$ ), which were contrary to mesoderm gene vimentin (Figure $1 \mathrm{D}, 1 \mathrm{H}, 1 \mathrm{~L}$ ). The RT-PCR analysis showed high expression of genes specific for iPSCs (OCT4, $N A N O G)$, and downregulation of pluripotency genes in iPS-MSCs and BMSCs. Meanwhile, vimentin, originally lowly expressed on iPSCs, was highly expressed on both iPS-MSCs and BMSCs (Figure 1M-1O). The results were consistent with the immunofluorescence detection.

The surface molecular hallmarks were detected of passage 6 iPS-MSCs by flow cytometric analysis. BMSCs served as a positive control, while iPSCs were also tested. The results showed that iPS-MSCs highly expressed CD73, CD90, CD105, and CD44 (larger than 95\%) with low expression of hematopoietic stem cell surface molecular 

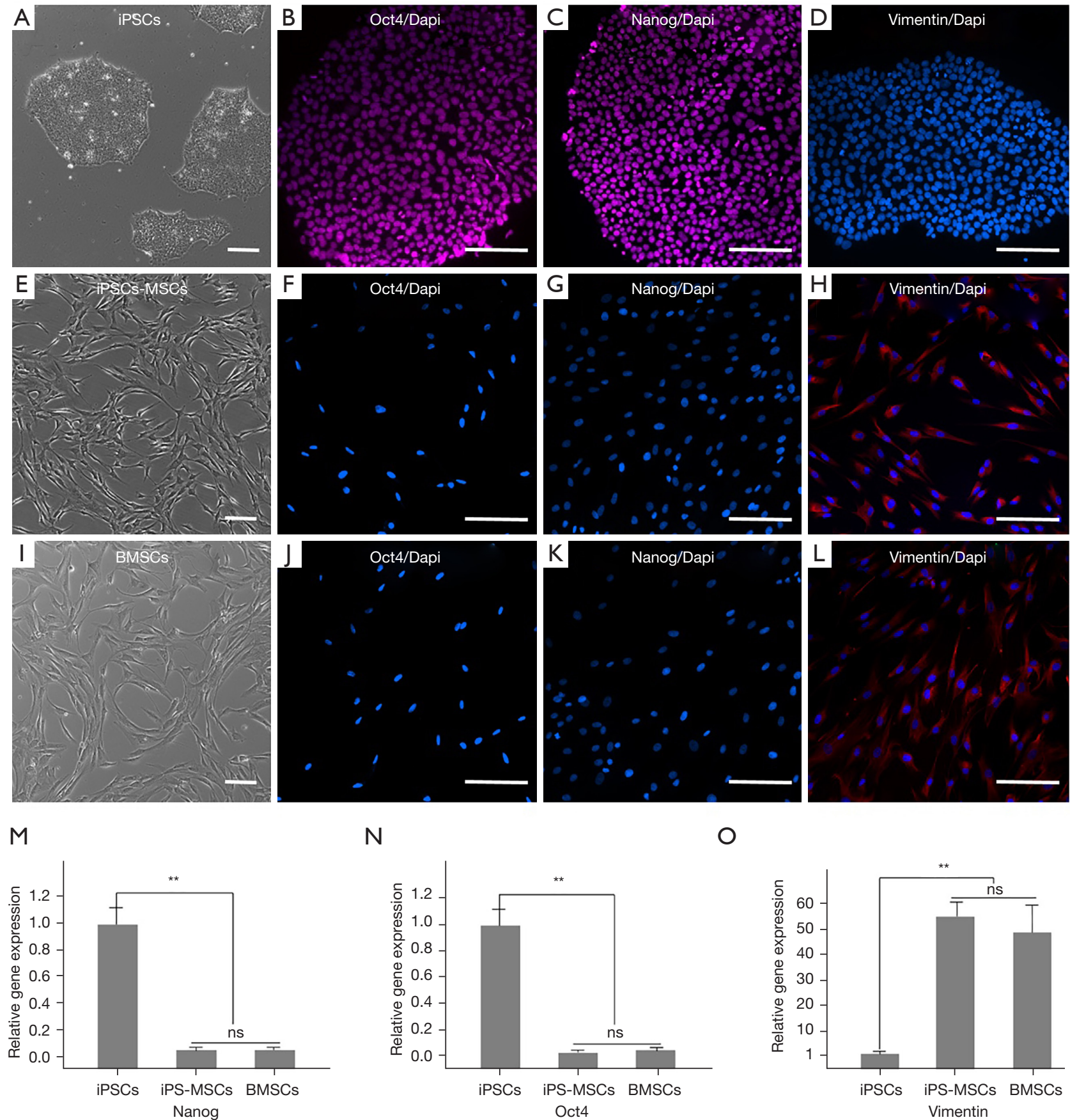

N
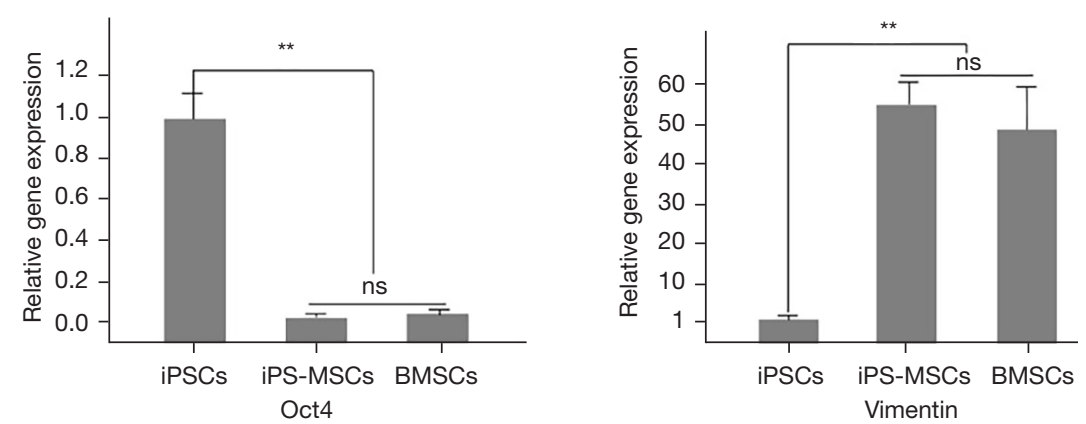

Figure 1 The cellular morphology and expression of pluripotency genes in iPS-MSCs, compared with iPSCs and BMSCs. (A) Clonal iPSCs, (B-D) Immunofluorescence staining for expression of OCT4, NANOG, vimentin in iPSCs; (E) P6 iPS-MSCs; (F-H) Immunofluorescence staining for expression of OCT4, NANOG, vimentin in iPS-MSCs; (I) P4 BMSCs; (J-L) Immunofluorescence staining for expression of OCT4, NANOG, vimentin in BMSCs. Red: marker protein; blue: cell nucleus. Scale bar, $200 \mu \mathrm{m}$. (M-O) Expression of OCT4, NANOG, and vimentin before and after differentiation of iPSCs into iPS-MSCs, BMSCs as control. ${ }^{* *} \mathrm{P}<0.01$; NS represents no difference. iPSCs, induced pluripotent stem cells; iPS-MSCs, induced pluripotent stem cells-mesenchymal stem cell-like cells; BMSCs, bone marrow mesenchymal stem cells. 
markers (CD34 and CD45), macrophage molecular marker CD14, lymphocyte molecular marker CD19, and HLA-DR (Figure 2), which were in compliance with the International Stem Cell Society for the surface molecular characterization of MSCs. Besides, the results showed that iPS-MSCs were similar to BMSCs, in addition to having low or no expression of the rest of the surface molecular markers except CD90.

We compared the capacity for tri-lineage differentiation after 21 days of iPS-MSCs and BMSCs (Figure 3). After osteogenic induction, a wide red area of calcium nodules could be seen under a microscope by Alizarin red staining, which indicated that the cells had good osteogenic differentiation function. Adipogenically differentiated cells were stained with oil red $\mathrm{O}$ and obvious lipid droplet formation was visible. After chondrogenic differentiation, the cells showed positive staining of Alcian blue, which indicated that they could differentiate into cartilage. In summary, iPS-MSCs had the same ability about multilineage differentiation as BMSCs.

To verify tumorigenicity, we injected iPS-MSCs subcutaneously into the hind limbs of NOD-SCID mice, which were also injected with iPSCs on the other side. After 8 weeks, clear tumor growth could be observed in mice transplanted with iPSCs, while the side of transplanted iPS-MSCs did not generate tumors even after dissection (Figure 4). It was obvious that iPS-MSCs were safer than iPSCs.

\section{Biocompatibility and osteogenic differentiation of iPSC- MSC seeded on $\mathrm{HA} / \mathrm{ZrO}_{2}$}

As reported in our previous study (9), the HA in powdered composites was transformed into $\mathrm{CaH}_{2} \mathrm{P}_{2} \mathrm{O}_{7}, \mathrm{Ca}_{2} \mathrm{P}_{2} \mathrm{O}_{7}$, $\mathrm{CaP}, \mathrm{CaH}_{2}$ phases. After being in contact with water, these nonhydrated phosphate phases could provide the necessary concentration of calcium and phosphate ions for bone mineralization. Meanwhile, high concentrations of calcium phosphate could form HA again in body temperature to stimulate bone formation. The addition of the inert $\mathrm{ZrO}_{2}$ greatly improved the biomechanical strength of the composite materials. The average flexural strength of materials was $898.67 \mathrm{MPa}$, which was much higher than the usage requirements of human weight-bearing sites. The $\mathrm{HA} / \mathrm{ZrO}_{2}$ porosity was 25 ppi and uniform with pore size of $150-300 \mu \mathrm{m}$. These were prepared as round pieces of different sizes according to experimental requirements. After iPS-MSCs and BMSCs were cultured on HA/
$\mathrm{ZrO}_{2}$ with normal medium for 7 days, under scanning electron microscopy (SEM), cells tightly adhered to the surface of the materials, spread out, and grew in a fibrous configuration, and spanned the pores on the surface of the materials with good condition (Figure 5). The CCK-8 studies showed that (Table 2), cells proliferated continuously in both culture solutions with increasing time, and the evaluation of cytotoxicity grade was grade 0 in both cultures. Therefore, iPS-MSCs and BMSCs can adhere, grow, proliferate, and differentiate well with $\mathrm{HA} / \mathrm{ZrO}_{2}$ in vitro. All experiments showed that $\mathrm{HA} / \mathrm{ZrO}_{2}$ had good biocompatibility.

We compared the osteogenic differentiation of iPSMSCs and BMSCs on $\mathrm{HA} / \mathrm{ZrO}_{2}$ materials at different times (7, 14, and 21 days) in vitro by detecting the expression of osteogenesis related genes (Runx2, COL1A1, ALP, and $O C N)$. The gene Runx 2 can promote early osteogenic differentiation as a key factor necessary for osteogenic differentiation of mesenchymal stem cells; Col1a1 is a kind of collagen associated with the formation of the extracellular matrix (ECM) of the pre-osteoblast, which progressively expresses $A L P$ during the maturation stage and then $O C N$ during the mineralization phase. First of all, the results of fluorescence qPCR showed that the expression of osteogenesis related genes in both iPS-MSCs and BMSCs increased significantly with time and there was no significant difference between the two groups (Figure 6A-6D). Besides, it was shown that both iPS-MSCs and BMSCs had a good mineralization ability on the $\mathrm{HA} / \mathrm{ZrO}_{2}$ materials after Alizarin red staining. With increasing time, the color was darker and the area of red larger, which indicated the increasing calcium nodule (Figure 6E). Furthermore, the results of calcium nodule quantification testing showed no significant difference in calcium content between the two types of cells during the same period (Figure 6F).

\section{Repairing effects of $\mathrm{HA} / \mathrm{ZrO} \mathrm{O}_{2}$ combined with IPS-MSCs on rat skull defects}

To validate the osteogenic capacity of iPS-MSCs in vivo, we used BMSCs as controls and individually combined with $\mathrm{HA} / \mathrm{ZrO}_{2}$ as composite materials after 7 days of osteogenic induction in vitro and then transplanted them into rats with skull bone defects. After 12 weeks, the results examined by micro-CT revealed that almost all defects transplanted by $\mathrm{HA} / \mathrm{ZrO}_{2}+\mathrm{iPS}_{-} \mathrm{MSC}$ group and $\mathrm{HA} / \mathrm{ZrO}_{2}+\mathrm{BMSC}$ group were repaired better than transplanting with $\mathrm{HA} / \mathrm{ZrO}_{2}$ alone group (Figure $7 A-7 C$ ). For bone mass analysis, the 

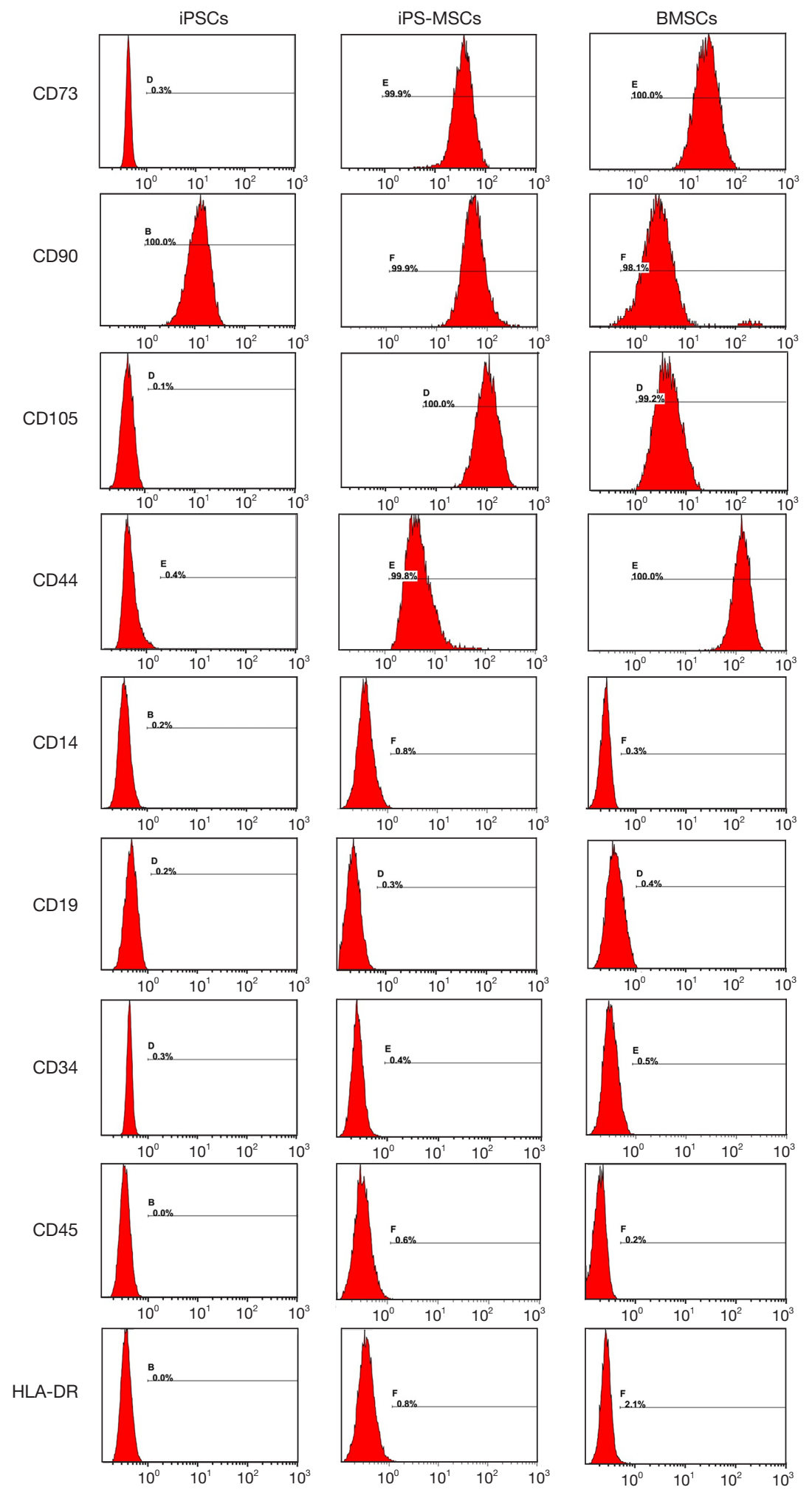

Figure 2 The surface molecular markers of iPSCs, iPS-MSCs and BMSCs. iPSCs, induced pluripotent stem cells; iPS-MSCs, induced pluripotent stem cells-mesenchymal stem cell-like cells. BMSCs, bone marrow mesenchymal stem cells. 

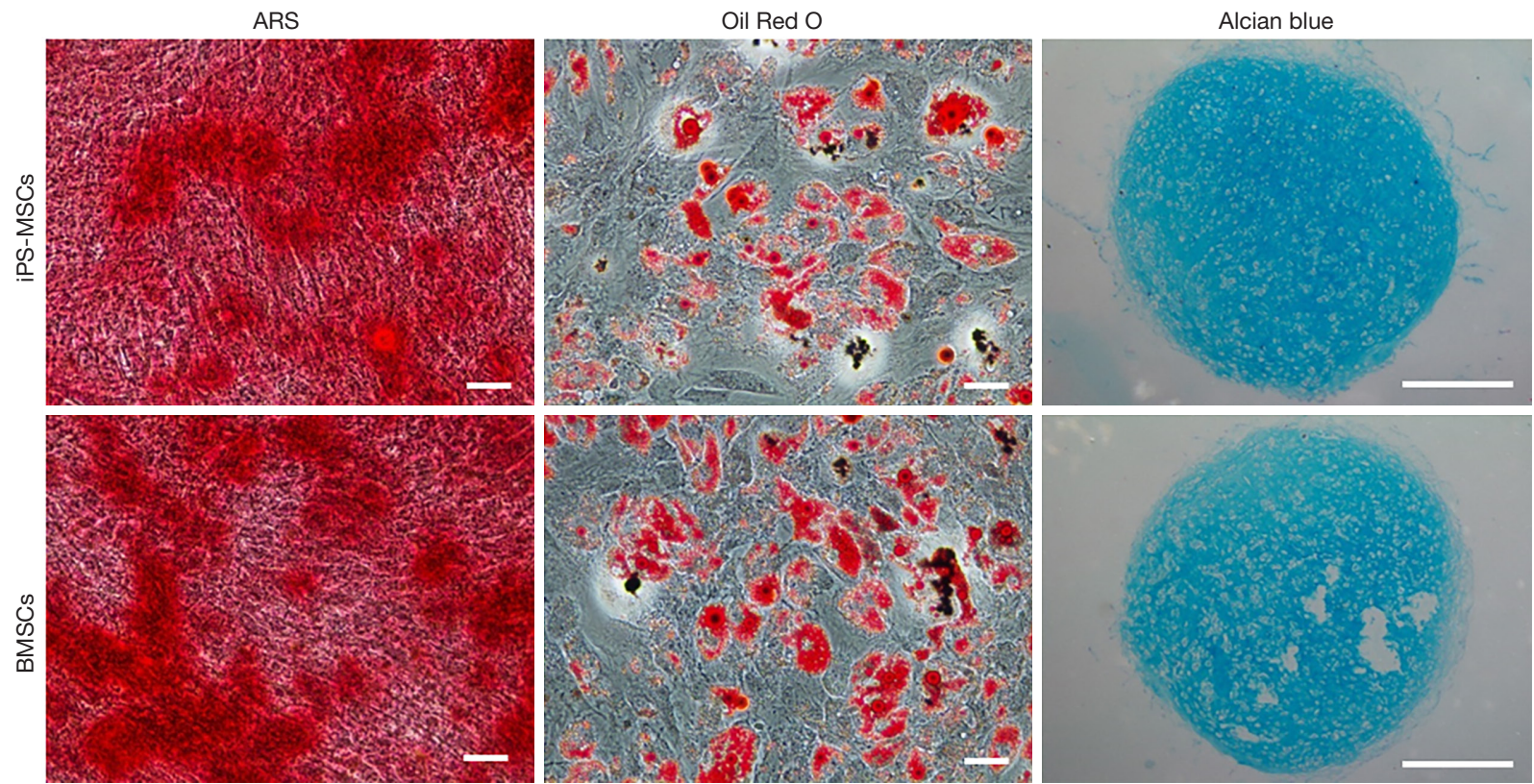

Figure 3 Multipotent differentiation capacity. Scale bar, $200 \mu \mathrm{m}$. ARS, Alizarin red staining; iPS-MSCs, induced pluripotent stem cellsmesenchymal stem cell-like cells; BMSCs, bone marrow mesenchymal stem cells.
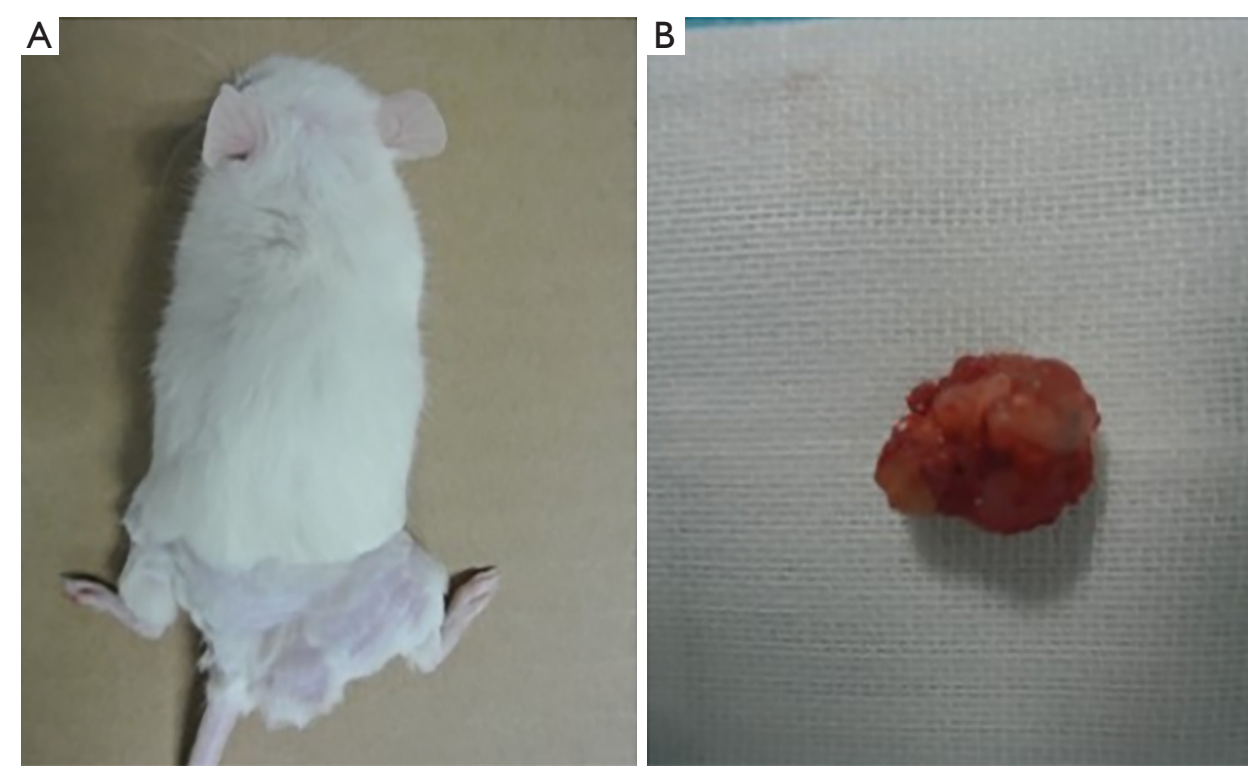

Figure 4 Teratoma formation test. (A) iPS-MSCs and iPSCs were transplanted on the left and right sides for 8 weeks, respectively; (B) iPSCs-generated tumors in mice. iPS-MSCs, induced pluripotent stem cells-mesenchymal stem cell-like cells; iPSCs, induced pluripotent stem cells. iPS-MSCs, induced pluripotent stem cells-mesenchymal stem cell-like cells. 

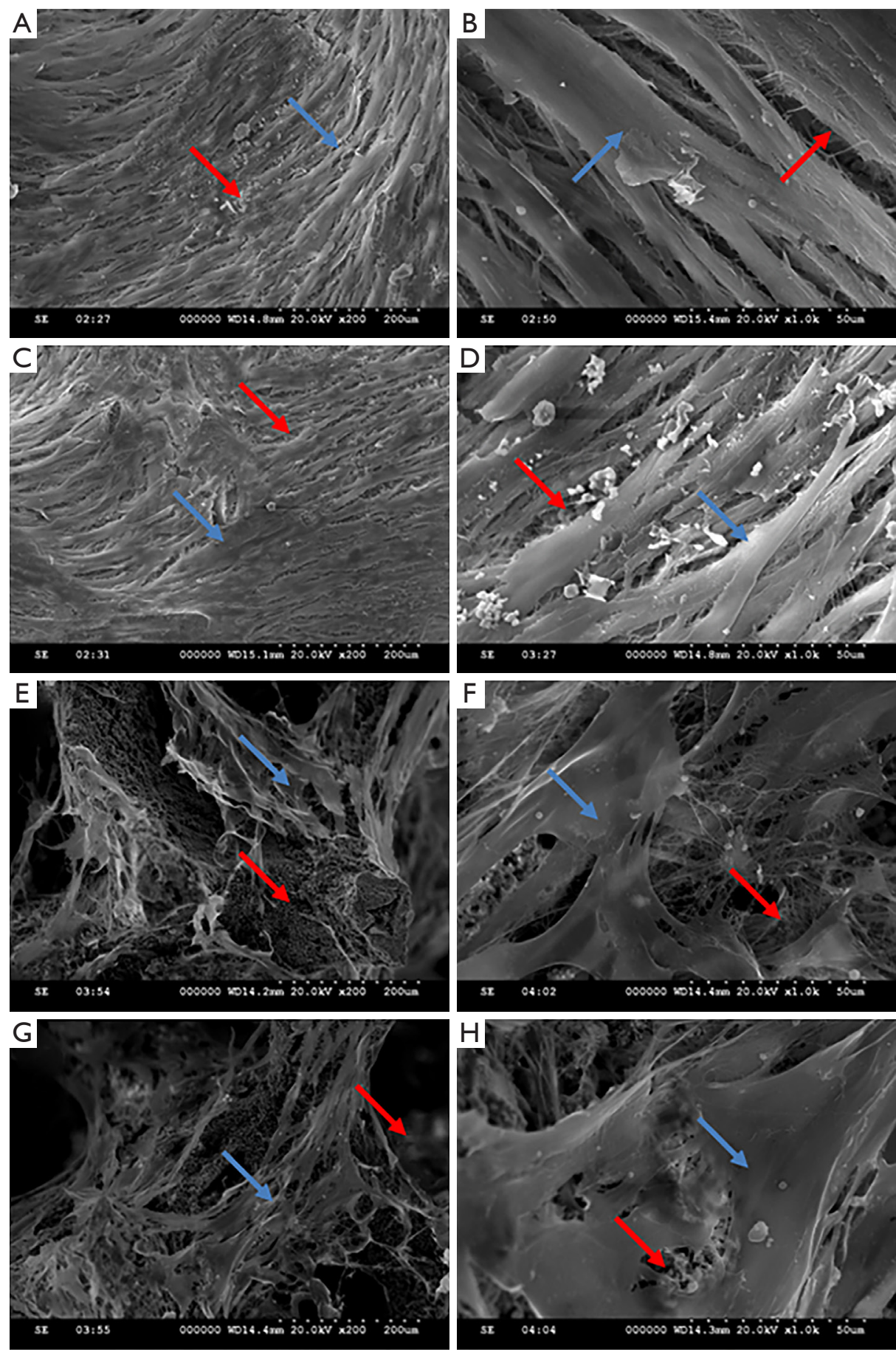

Figure 5 The cell-growth on the materials was examined by SEM. SEM, scanning electron microscopy. The internal structure of $\mathrm{HA}_{2} \mathrm{ZrO}{ }_{2}$ materials were dense and porous, which presented a tridimensional distribution. The blue arrow indicated that both iPS-MSCs and BMSCs tightly adhered to the surface of the materials, spread out and grew in a fibrous configuration. The red arrow indicated that all the cells spanned the pores on the surface of the materials with good condition. (A-D) Under different magnifications, iPS-MSCs growing on the surface of the materials were observed; (E-H) BMSCs growing on the surface of the materials were observed under different magnifications. iPS-MSCs, induced pluripotent stem cells-mesenchymal stem cell-like cells; BMSCs, bone marrow mesenchymal stem cells. 
Table 2 CCK- 8 assays for proliferation analysis

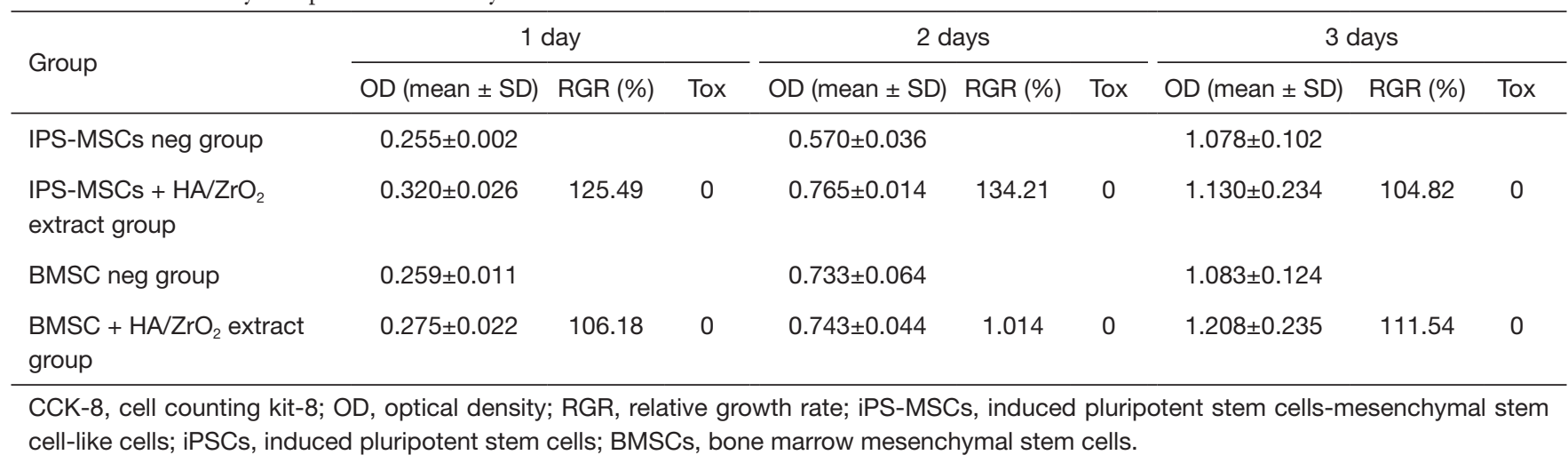

values of volume bone mineral density (vBMD), new bone formation volume (BV), and percent new bone formation volume (BV/TV) in both $\mathrm{HA} / \mathrm{ZrO}_{2}$ combined with iPSMSCs or BMSCs groups were significantly higher than those in the $\mathrm{HA} / \mathrm{ZrO}_{2}$ alone group (Figure $7 D-7 F$ ).

\section{Discussion}

The MSCs belong to adult stem cells and have a strong ability to self-renew and proliferate. They can be transformed into bone cells, adipocytes, nerve cells, muscle cells, and endothelial cells under different induction conditions. They have many advantages such as being easy to manipulate gene and weak immunogenicity, which gradually becomes an appropriate cell carrier for gene therapy. At present, although the treatment of BMSCs has been more widely applied in the clinic (10-12), several factors limit their further clinical applications. Firstly, the acquisition of BMSCs is an invasive operation, and the number of BMSCs provided by patients themselves is limited. Besides, there are individualized differences in the activities of MSCs, such as disease, age, and other factors. Moreover, poor pericellular environment such as inflammatory reaction, immune rejection, hypoxia, and oxidative stress also decreases the ability of BMSCs (13).

There are similarities between iPSCs and ESCs in morphology, epigenetic modifications, gene and protein expression, and iPSCs have great potential regarding selfrenewal, high proliferation, and multilineage differentiation. They can be reprogrammed from differentiated mature cells, which solve the ethical concerns of ESCs. Besides, iPSCs are induced from patients' autologous cells so that they avoid immune rejection. With the development of reprogramming technology, iPSCs derived by induction with adenovirus, transient expression of plasmid vectors, or recombinant proteins have a lower tumorigenic risk. Some results have shown that hiPSCs-derived MSCs have higher telomerase activity, and better immunomodulation and tissue repair abilities than MSCs. No tumor was observed in animals after implanting iPS-MSCs, which indicates their security. The investigators also contrasted the finding that iPS-MSCs have a greater capacity for vascular repair than BMSCs. All studies have indicated that iPS-MSCs are more promising for cell therapy and regenerative medicine (14-17).

At present, there have been several reports on the methods of iPSCs or ESCs differentiated into MSCs, including spontaneous differentiation in embryoid bodies (EBs) or inducing and differentiating directly in conditioned media (18-22). Inducting EBS differentiation is a classical method, and iPSCs can differentiate into the inner cell mass of spherical blastocyst under a specific suspension culture. Mature EBs include many types of cells which represent derivatives of the 3 embryonic germ layers. However, the procedure of differentiation in EBS is tedious, is more timeconsuming, and is considered inefficient. The methods of direct conditioned medium induction are mostly achieved by the way of adding cytokines and small molecule compounds, but also by using direct culture with BMSCs and iPSCs or ESs after serial passage to acquire MSCs. During the differentiation of iPSCs, the transforming growth factor- $\beta$ (TGF- $\beta$ ) pathway maintains stemness of iPS cells. Acting as a TGF- $\beta$ signal inhibitor, SB431542 can promote the differentiation of iPSCs (23-25).

In this study, we cultured BMSCs in the presence of SB431542, combined with the method of serial subculture to induce iPS cells. For 7 consecutive days in medium supplemented with $10 \mathrm{uM} \mathrm{SB} 431542$, the first passage was performed with milder accutase enzymatic digestion. 
A

Runx2

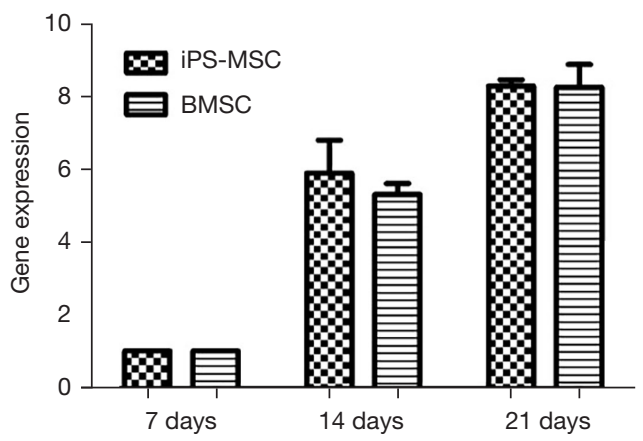

Col1a1

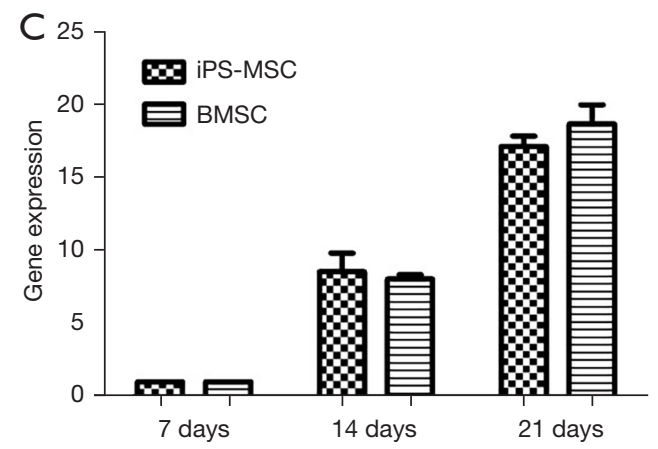

$E$

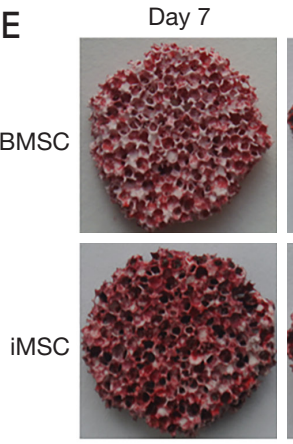

Day 14
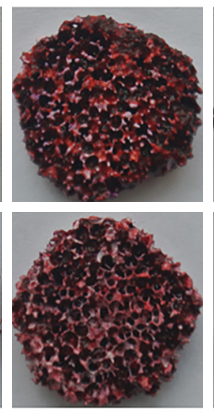

Day 21

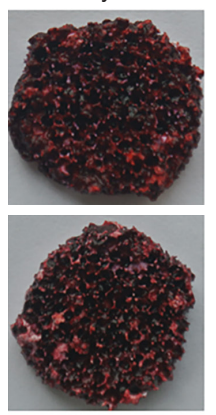

B

ALP

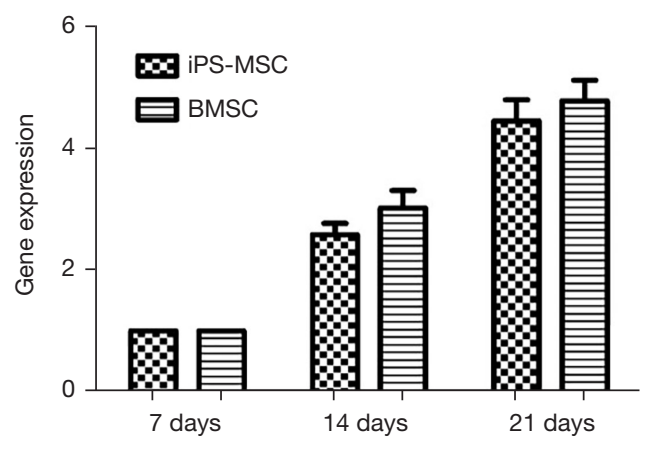

OCN
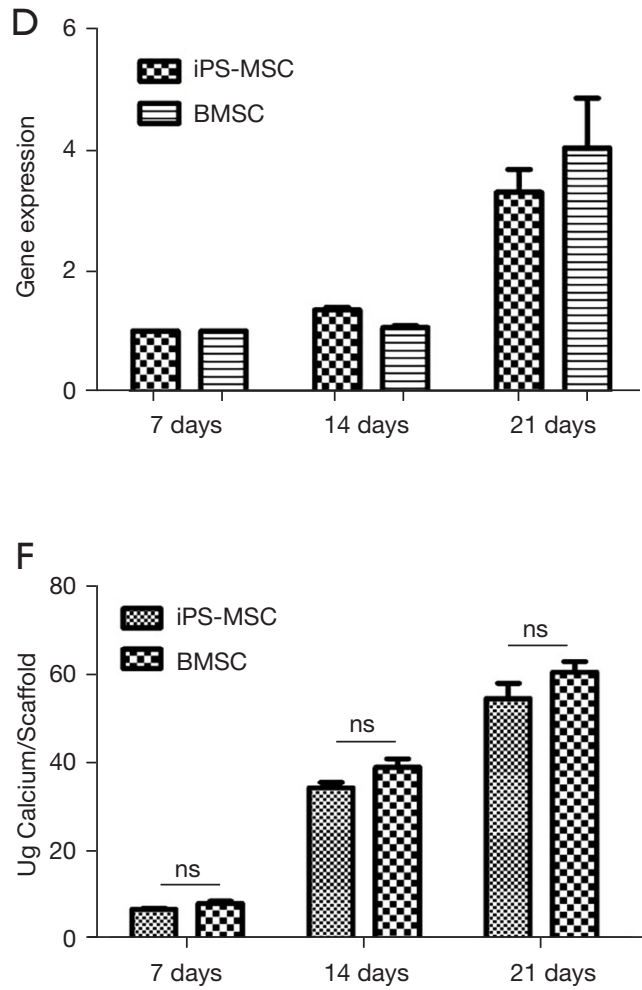

Figure 6 The tests about osteogenic differentiation of iPS-MSCs and BMSCs. (A-D) The expression of osteogenesis related genes (Runx2, COL1A1, ALP, and $O C N$ ) in iPS-MSCs and BMSCs on days 7, 14, and 21. (E) Alizarin red staining used in osteogenic differentiation of iPSMSCs and BMSCs on $\mathrm{HA} / \mathrm{ZrO}_{2}$ at 7, 14, and 21 days. (F) Calcium nodule quantification test about osteogenic differentiation of iPSMSCs and BMSCs on $\mathrm{HA} / \mathrm{ZrO}_{2}$ at 7, 14, and 21 days. iPS-MSCs, induced pluripotent stem cells-mesenchymal stem cell-like cells; BMSCs, bone marrow mesenchymal stem cells.

The cells were full 3-4 days after passaging, and after another passage, spindle cells similar to those of BMSCs appeared. From the induction to obtaining BMSC-like cells, it takes only about 2 weeks, as a result of which the time of induction is greatly shortened. According to the 2006 International Society for stem cells (ISCT) identification criteria for human MSCs (26): (I) MSCs can grow adherently under standard culture conditions; (II) MSCs express CD105, CD73, and CD90 and do not express CD45, CD14, CD11b, HLA-DR, CD79 $\alpha$, or CD19, in which the positive rate of CD73, CD90, and CD105 should be $\geq 95 \%$ and the positive rate of other 


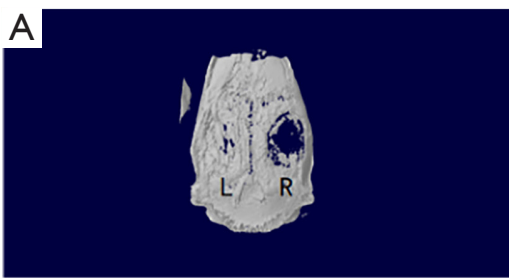

$\mathrm{D}$

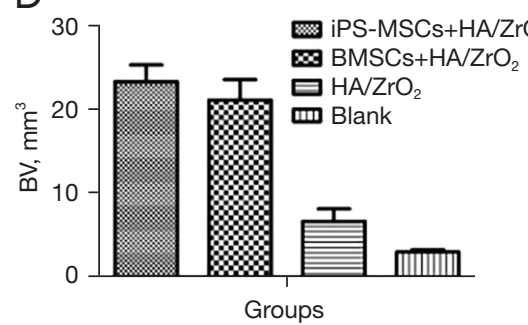

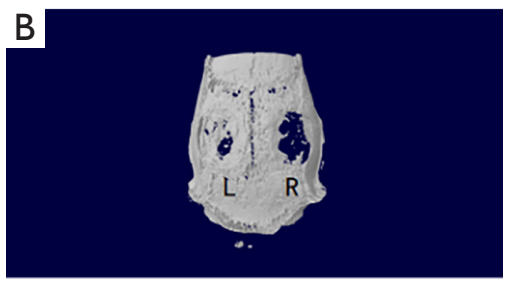

$\mathrm{E}$

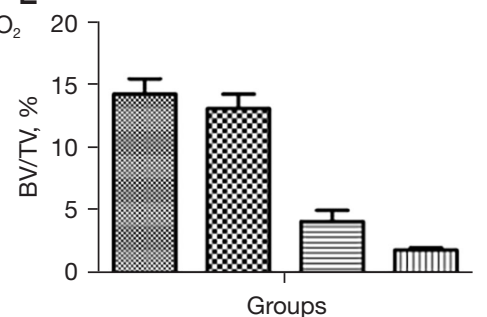

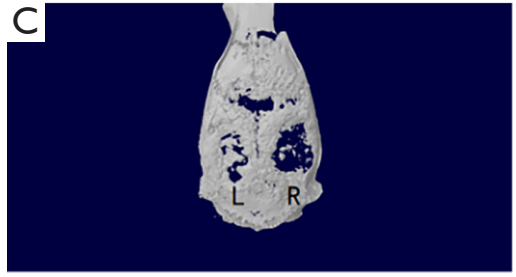

$\mathrm{F}$

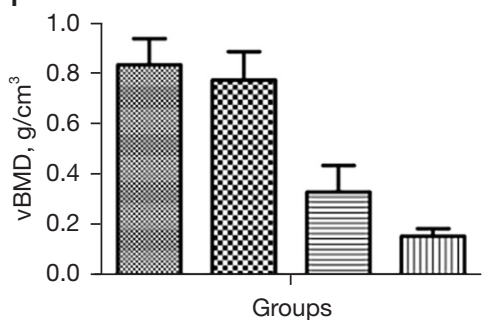

Figure 7 Micro-CT examination and bone mass analysis. (A) The left hole was transplanted by iPS-MSCs $+\mathrm{HA}^{\mathrm{Z}} \mathrm{ZrO} 2$, the right hole was a blank control. (B) The left hole was BMSCs $+\mathrm{HA} / \mathrm{ZrO}_{2}$, the right hole was a blank control. (C) The left hole was $\mathrm{HA} / \mathrm{ZrO}{ }_{2}$, the right hole was a blank control. (D-F) The bone mass comparison in BV, BV/TV and vBMD. iPS-MSCs, induced pluripotent stem cells-mesenchymal stem cell-like cells; BMSCs, bone marrow mesenchymal stem cells; BV, new bone formation volume; BV/TV, percent new bone formation volume; vBMD, volume bone mineral density.

negative markers should be $\leq 2 \%$; (III) MSCs have the ability of 3-way differentiation of osteogenic, adipogenic, and chondrogenic in vitro. Flow cytometric analysis used in surface markers of iPSC BMSCs, BMSCs, and hiPSCs revealed that iPSCs expressed the surface molecules CD44, CD73, CD105, CD90, CD14, CD19, CD34, CD45, and HLA-DR before differentiation from $0.4 \%, 0.3 \%$, $0.1 \%, 100 \%, 0.2 \%, 0.2 \%, 0.3 \%, 0 \%, 0 \%$ into $99.8 \%$, 99. $9 \%, 100 \%, 99.9 \%, 0.8 \%, 0.3 \%, 0.4 \%, 0.6 \%, 0.8 \%$, which were similar with the BMSCs as control expressing $100 \%, 100 \%, 99.2 \%, 98.1 \%, 0.3 \%, 0.4 \%, 0.5 \%, 0.2 \%$, and $2.1 \%$. Using immunofluorescence staining to contrast the expression of related proteins before and after iPSCs differentiated, it was shown that iPS-differentiated cells did not express the pluripotency marker protein OCT4 and the ectoderm marker protein Nestin, but did express the mesoderm marker protein vimentin (27). The iPS-BMSCs were induced for osteogenic, adipogenic, and chondrogenic differentiation, and after 21 days stained positive with Alizarin red, oil red $\mathrm{O}$, and Alcian blue. The results were consistent with qRT-PCR related gene assays. The above results befit the definition of MSCs by ISCT, indicating the successful establishment of a highly efficient method for differentiating iPSCs into MSCs.

The application of tissue-engineered bone to repair bone defects is a hot spot in current clinical medicine
(28-30). As a scaffold for cells, the selection criteria of tissue-engineering bone scaffold materials include: (I) excellent biomimetic properties. Bone tissue is a structure with $3 \mathrm{D}$ porousness, which is conducive to the metabolic absorption of nutrients. Artificial scaffold materials also need a porous structure similar to bone tissue, which is conducive to the ingrowth of cells and better promotes the reconstruction of bone repair; (II) a certain mechanical strength; (III) good osteoconductive and osteoinductive effect; (IV) be degradable. The degradative components of scaffold material are similar to bone composition, which not only cause no toxicity but also promote the generation of bone. Currently, cell scaffolds used for bone repair mainly include fiber scaffolds, microspheres, porous scaffolds, hydrogels and composite scaffolds (31). Hydroxyapatite (HA), a bioactive material close to natural apatite mineral, is the major inorganic substance of human bone (32-34). After implantation, HA will be partially degraded to release the necessary calcium and phosphorus, after which the elements will be absorbed, utilized, and incorporated into new tissues, so that the HA implant and bone tissues can be well integrated. HA can facilitate the formation of extracellular matrix including collagen I, fibronectin, peptides, growth factors, glucosamine, and other active molecules, which activate the related signaling pathways for the adsorption of stem cells onto biomaterials (35). In a study by Shie 
et al. (36), inhibition of MAPK/ERK and MAPK/p38 signaling pathways significantly decreased the adhesion, proliferation, and differentiation of hMSCs and HDPCs in calcium silicate cement. Chen et al. (37) found that the adhesion and osteogenic differentiation of BMSCs cultured on a HA-coated surface could be better after using low-magnitude and high-frequency vibrations, while the Wnt10B, $\beta$-catenin, Runx 2 and osterix were significantly increased, as a result of which vibration may directly induce osteogenesis by activating the $\mathrm{Wnt} / \beta$-catenin signaling pathway. Although HA has good osteoconductivity, osteoinductivity, and biocompatibility (38), simple HA as a scaffold material has defects such as low strength, poor toughness, and degranulation. Being fabricated into porous materials further reduces the flexural strength and fracture toughness of HA, as a result of which the scaffold material with single HA cannot meet the requirements for bone replacement in load-bearing parts of the human body. Zirconium dioxide $\left(\mathrm{ZrO}_{2}\right)$ is a mineral raw material of zirconia with a very high density, the hardness of which is second only to diamond. Besides, it has a good biocompatibility, without allergy, irritation, corrosion, or other adverse reactions (38-40). Combining $\mathrm{HA}$ and $\mathrm{ZrO}_{2}$ to prepare $\mathrm{HA} / \mathrm{ZrO}_{2}$ composites both improved the physical strength of $\mathrm{HA}$ and retained the good biocompatibility of HA. In this study, the porous composites of $\mathrm{HA} / \mathrm{ZrO}_{2}$ were prepared by gradient recombination by high-temperature sintering adding pore former. Adjusting the strength by changing the $\mathrm{HA} / \mathrm{ZrO}_{2}$ voids can produce highly simulated artificial bone materials with mechanical properties that most closely resemble natural bone. Biomechanical examination revealed that $\mathrm{HA} / \mathrm{ZrO}_{2}$ composites exhibited an average flexural strength of 898.6 MPa, which could reach up to $1,112.6 \mathrm{MPa}$, far exceeding the natural bone strength in humans $(41,42)$.

Subsequently we used MSCs differentiated from hiPSCs to construct novel tissue-engineered bone by seeding in HA/ $\mathrm{ZrO}_{2}$ porous foam ceramic materials, and then examining the biocompatibility. Seeding iPS-MSCs and BMSCs on HA/ $\mathrm{ZrO}_{2}$ for SEM at days 2, 7, and 14 showed that both cells adhered to the surface of the materials, proliferated well, and gradually grew into the internal voids of the materials. The CCK-8 assay was used to detect cell proliferation, and the OD values of the cells cultured with the extract of the dip solution from $\mathrm{HA} / \mathrm{ZrO}_{2}$ showed a gradual increase on days 1,4 , and 7 , which were not significantly different in the control cells cultured in complete medium. The cytotoxic grade ratings of $\mathrm{HA} / \mathrm{ZrO}_{2}$ were all grade 0 , which indicated that $\mathrm{HA} / \mathrm{ZrO}_{2}$ porous foam ceramic materials had good biosafety. We seeded iPS-MSCs and BMSCs on $\mathrm{HA} / \mathrm{ZrO}_{2}$ porous materials, respectively, for osteogenic induction and differentiation in vitro, after which we performed calcium nodule assay by Alizarin red staining and related gene of osteogenesis expression assay at different time points (days 7,14 , and 21) to compare the osteogenic potential of the 2 cells on $\mathrm{HA} / \mathrm{ZrO}_{2}$ materials. The results showed that both iPS-MSCs and BMSCs composite materials were deeply stained with Alizarin red dye solution over time. Besides, the quantitative analysis of calcium content showed that calcium content gradually increased in both groups, indicating that iPS-MSCs have a good osteogenic capacity like BMSCs. The results of qRT-PCR confirmed that Runx2, Col1a1, ALP, and $O C N$ expressions all increased with time, in which $O C N$ reached a high value at day 21 . As a specific transcriptional regulator (43), Runx2 is necessary and sufficient for osteogenic differentiation of BMSCs. The expression of Runx 2 can promote the transcriptional maturation of osteogenesis-related protein genes and the sustained expression of Runx2 is beneficial to the progress of osteogenic differentiation (44). The gene Col1a1 is an important marker of osteogenic differentiation, which accounts for more than $90 \%$ of the bone matrix and is an important component of osteogenesis $(45,46)$. As an essential enzyme in osteogenesis, $A L P$ can hydrolyze organic phosphate, release inorganic phosphorus, and then form hydroxyapatite, which is a marker about early maturation in osteogenic differentiation of MSCs $(45,47)$. The ECM protein $O C N$ is only found in the ECM secreted of osteoblasts currently. Its appearance marks the beginning of the mineralization phase in osteogenic differentiation, which is well recognized as a marker of mature osteoblast differentiation $(48,49)$. The results illustrated that HA/ $\mathrm{ZrO}_{2}$ could promote the osteogenic differentiation of iPSMSCs from BMSCs. Finally, we transplanted iPS-MSCs on $\mathrm{HA} / \mathrm{ZrO}_{2}$ to repair rat calvarial defects. At 28 days after transplantation, the calvarial defects repaired by iPS-MSCs $+\mathrm{HA} / \mathrm{ZrO}_{2}$ composite healed at a rate close to that of bone defects repaired by BMSCs $+\mathrm{HA} / \mathrm{ZrO}_{2}$ composite. All of them were faster than the control group, which indicated that $\mathrm{HA} / \mathrm{ZrO}_{2}$ not only has good biocompatibility, but also can promote osteogenesis and accelerate the healing of bone defects later.

\section{Conclusions}

In conclusion, we obtained IPSC-MSCs by inducing UC- 
derived iPSCs, which were characterized by phenotype, gene, and multi-differentiating capacity resembling normal human BMSCs. The iPSC-MSCs were able to continue their proliferation and osteogenic differentiation like BMSCs after being seeded on $\mathrm{HA} / \mathrm{ZrO}_{2}$. Likewise, the compound of iPS-MSCs and $\mathrm{HA} / \mathrm{ZrO}_{2}$ can promote the healing of calvarial defects in rats after transplantation. This study provides a novel approach for bone tissue engineering, and a substantial reference about iPSC-based therapy for bone tissue repair and orthopedic diseases.

\section{Acknowledgments}

We thank Dr. Cui Zhang, Dr. Cuicui Wang, and Dr. Liang Li in College of Life Sciences of Zhejiang University for their valuable suggestions and advice.

Funding: This study was supported by Zhejiang Medical and Health Science and Technology Project (2014KYA191) and Major Science and Technology Projects in Zhejiang Province (2014C03031).

\section{Footnote}

Reporting Checklist: The authors have completed the ARRIVE reporting checklist. Available at https://dx.doi. org/10.21037/atm-21-5402

Data Sharing Statement: Available at https://dx.doi. org/10.21037/atm-21-5402

Conflicts of Interest: All authors have completed the ICMJE uniform disclosure form (available at https://dx.doi. org/10.21037/atm-21-5402). The authors have no conflicts of interest to declare.

Ethical Statement: The authors are accountable for all aspects of the work in ensuring that questions related to the accuracy or integrity of any part of the work are appropriately investigated and resolved. All procedures performed in this study involving human participants were in accordance with the Declaration of Helsinki (as revised in 2013). The study was approved by the Ethics Committee of Xiaoshan Hospital of Traditional Chinese Medicine (No. 2014396) and informed consent was taken from all the patients. Animals experiments were performed under a project license (No. 10296) granted by the Ethics Committee of Xiaoshan Hospital of Traditional Chinese Medicine, in compliance with the hospital guidelines for the care and use of animals.

Open Access Statement: This is an Open Access article distributed in accordance with the Creative Commons Attribution-NonCommercial-NoDerivs 4.0 International License (CC BY-NC-ND 4.0), which permits the noncommercial replication and distribution of the article with the strict proviso that no changes or edits are made and the original work is properly cited (including links to both the formal publication through the relevant DOI and the license). See: https://creativecommons.org/licenses/by-nc-nd/4.0/.

\section{References}

1. Kashirina A, Yao Y, Liu Y, et al. Biopolymers as bone substitutes: a review. Biomater Sci 2019;7:3961-83.

2. Kagami H, Agata H, Tojo A. Bone marrow stromal cells (bone marrow-derived multipotent mesenchymal stromal cells) for bone tissue engineering: basic science to clinical translation. Int J Biochem Cell Biol 2011;43:286-9.

3. Hasan A, Byambaa B, Morshed M, et al. Advances in osteobiologic materials for bone substitutes. J Tissue Eng Regen Med 2018;12:1448-68.

4. Illich DJ, Demir N, Stojković M, et al. Concise review: induced pluripotent stem cells and lineage reprogramming: prospects for bone regeneration. Stem Cells 2011;29:555-63.

5. Mu L, Sui W, Lin Y, et al. Androgen attenuates antitumor effects of gastric cancer cells by bone marrow mesenchymal stem cells via restricting the JNK signaling activation. Transl Cancer Res 2019;8:917-27.

6. Lim JM, Gong SP. Somatic cell transformation into stem cell-like cells induced by different microenvironments. Organogenesis 2013;9:245-8.

7. Zhou M, Xi J, Cheng Y, et al. Reprogrammed mesenchymal stem cells derived from iPSCs promote bone repair in steroid-associated osteonecrosis of the femoral head. Stem Cell Res Ther 2021;12:175.

8. Lian Q, Zhang Y, Zhang J, et al. Functional mesenchymal stem cells derived from human induced pluripotent stem cells attenuate limb ischemia in mice. Circulation 2010;121:1113-23.

9. Xie S, Quan R, Qi J, et al. Biological interface study of $\mathrm{HA} / \mathrm{ZrO} 2$ graded composite in a dog lumbar vertebra bone defect model. Composite Interfaces 2014;9:151-65.

10. Moghadasi S, Elveny M, Rahman HS, et al. A paradigm shift in cell-free approach: the emerging role of MSCsderived exosomes in regenerative medicine. J Transl Med 
2021;19:302.

11. Xiao Y, Peng J, Liu Q, et al. Ultrasmall CuS@BSA nanoparticles with mild photothermal conversion synergistically induce MSCs-differentiated fibroblast and improve skin regeneration. Theranostics 2020;10:1500-13.

12. Atluri S, Manchikanti L, Hirsch JA. Expanded Umbilical Cord Mesenchymal Stem Cells (UC-MSCs) as a Therapeutic Strategy in Managing Critically Ill COVID-19 Patients: The Case for Compassionate Use. Pain Physician 2020;23:E71-83.

13. Shu P, Sun DL, Shu ZX, et al. Therapeutic Applications of Genes and Gene-Engineered Mesenchymal Stem Cells for Femoral Head Necrosis. Hum Gene Ther 2020;31:286-96.

14. Stosich MS, Bastian B, Marion NW, et al. Vascularized adipose tissue grafts from human mesenchymal stem cells with bioactive cues and microchannel conduits. Tissue Eng 2007;13:2881-90.

15. Johnson PC, Mikos AG, Fisher JP, et al. Strategic directions in tissue engineering. Tissue Eng 2007;13:2827-37.

16. Arvidson K, Abdallah BM, Applegate LA, et al. Bone regeneration and stem cells. J Cell Mol Med 2011;15:718-46.

17. Shanti RM, Li WJ, Nesti LJ, et al. Adult mesenchymal stem cells: biological properties, characteristics, and applications in maxillofacial surgery. J Oral Maxillofac Surg 2007;65:1640-7.

18. Sheyn D, Ben-David S, Shapiro G, et al. Human Induced Pluripotent Stem Cells Differentiate Into Functional Mesenchymal Stem Cells and Repair Bone Defects. Stem Cells Transl Med 2016;5:1447-60.

19. Zhang J, Lian Q, Zhu G, et al. A human iPSC model of Hutchinson Gilford Progeria reveals vascular smooth muscle and mesenchymal stem cell defects. Cell Stem Cell 2011;8:31-45.

20. Lian Q, Lye E, Suan Yeo K, et al. Derivation of clinically compliant MSCs from CD105+, CD24- differentiated human ESCs. Stem Cells 2007;25:425-36.

21. Villa-Diaz LG, Brown SE, Liu Y, et al. Derivation of mesenchymal stem cells from human induced pluripotent stem cells cultured on synthetic substrates. Stem Cells 2012;30:1174-81.

22. Gao F, Chiu SM, Motan DA, et al. Mesenchymal stem cells and immunomodulation: current status and future prospects. Cell Death Dis 2016;7:e2062.

23. Hannan NR, Jamshidi P, Pera MF, et al. BMP-11 and myostatin support undifferentiated growth of human embryonic stem cells in feeder-free cultures. Cloning Stem Cells 2009; 11:427-35.

24. Vallier L, Pedersen RA. Human embryonic stem cells: an in vitro model to study mechanisms controlling pluripotency in early mammalian development. Stem Cell Rev 2005;1:119-30.

25. Touboul T, Hannan NR, Corbineau S, et al. Generation of functional hepatocytes from human embryonic stem cells under chemically defined conditions that recapitulate liver development. Hepatology 2010;51:1754-65.

26. Gratama J, Kvalheim G, Orfao A. Standardization of cell analysis methods in clinical cellular therapy programs: A challenge for ISCT. Cytotherapy 2006;8:528-9.

27. Lou AN, Pan CQ, Li Y, et al. Effect of bile duct ligation and recanalization on rat hepatocyte epithelialmesenchymal phenotype and NOX4 protein expression. Nan Fang Yi Ke Da Xue Xue Bao 2015;35:1457-62.

28. Amini AR, Laurencin CT, Nukavarapu SP. Bone tissue engineering: recent advances and challenges. Crit Rev Biomed Eng 2012;40:363-408.

29. O'Keefe RJ, Mao J. Bone tissue engineering and regeneration: from discovery to the clinic--an overview. Tissue Eng Part B Rev 2011;17:389-92.

30. Ducheyne P, Mauck RL, Smith DH. Biomaterials in the repair of sports injuries. Nat Mater 2012;11:652-4.

31. Turnbull G, Clarke J, Picard F, et al. 3D bioactive composite scaffolds for bone tissue engineering. Bioact Mater 2018;3:278-314.

32. Jeong KJ, Song Y, Shin HR, et al. In vivo study on the biocompatibility of chitosan-hydroxyapatite film depending on degree of deacetylation. J Biomed Mater Res A 2017;105:1637-45.

33. Moroi A, Okuno M, Kobayashi G, et al. Effect on surface character and mechanical property of unsintered hydroxyapatite/poly-l-lactic acid (uHA/PLLA) material by UV treatment. J Biomed Mater Res B Appl Biomater 2018;106:191-200.

34. Liang YH, Liu CH, Liao SH, et al. Cosynthesis of cargoloaded hydroxyapatite/alginate core-shell nanoparticles (HAP@Alg) as pH-responsive nanovehicles by a pre-gel method. ACS Appl Mater Interfaces 2012;4:6720-7.

35. Gao C, Peng S, Feng P, et al. Bone biomaterials and interactions with stem cells. Bone Res 2017;5:17059.

36. Shie MY, Ding SJ. Integrin binding and MAPK signal pathways in primary cell responses to surface chemistry of calcium silicate cements. Biomaterials 2013;34:6589-606.

37. Chen B, Lin T, Yang X, et al. Low-magnitude, highfrequency vibration promotes the adhesion and the 
osteogenic differentiation of bone marrow-derived mesenchymal stem cells cultured on a hydroxyapatitecoated surface: The direct role of $W n t / \beta$-catenin signaling pathway activation. Int J Mol Med 2016;38:1531-40.

38. D'Elía NL, Mathieu C, Hoemann CD, et al. Bone-repair properties of biodegradable hydroxyapatite nano-rod superstructures. Nanoscale 2015;7:18751-62.

39. Calvo-Guirado JL, Aguilar-Salvatierra A, Delgado-Ruiz RA, et al. Histological and Histomorphometric Evaluation of Zirconia Dental Implants Modified by Femtosecond Laser versus Titanium Implants: An Experimental Study in Fox Hound Dogs. Clin Implant Dent Relat Res 2015;17:525-32.

40. Khan SA, Fu Z, Wang W, et al. Hierarchical m-ZrO2 Nanorods Template-Free Synthesis by Hydrothermal Method. International Journal of Applied Ceramic Technology 2014;11:590-3.

41. Ozeki K, Goto T, Aoki H, et al. Fabrication of hydroxyapatite thin films on zirconia using a sputtering technique. Biomed Mater Eng 2014;24:1793-802.

42. Yang J, Sultana R, Hu X, et al. Novel Layered Hydroxyapatite/Tri-Calcium Phosphate-Zirconia Scaffold Composite with High Bending Strength for Load-Bearing Bone Implant Application. International Journal of Applied Ceramic Technology 2014;11:22-30.

43. Ducy P, Starbuck M, Priemel M, et al. A Cbfa1-dependent genetic pathway controls bone formation beyond

Cite this article as: Zhou L, Quan R, Yang J, Xu H. Healing of bone defects by induced pluripotent stem cell-derived bone marrow mesenchymal stem cells seeded on hydroxyapatitezirconia. Ann Transl Med 2021;9(23):1723. doi: 10.21037/ atm-21-5402 embryonic development. Genes Dev 1999;13:1025-36.

44. Zhang X, Aubin JE, Inman RD. Molecular and cellular biology of new bone formation: insights into the ankylosis of ankylosing spondylitis. Curr Opin Rheumatol 2003;15:387-93.

45. Cheng M, Qiao Y, Wang Q, et al. Calcium Plasma Implanted Titanium Surface with Hierarchical Microstructure for Improving the Bone Formation. ACS Appl Mater Interfaces 2015;7:13053-61.

46. Orosa B, Martínez P, González A, et al. Effect of lysophosphatidic acid receptor inhibition on bone changes in ovariectomized mice. J Bone Miner Metab 2015;33:383-91.

47. Vieira AE, Repeke CE, Ferreira Junior Sde B, et al. Intramembranous bone healing process subsequent to tooth extraction in mice: micro-computed tomography, histomorphometric and molecular characterization. PLoS One 2015;10:e0128021.

48. Tanaka K, Kaji H, Yamaguchi T, et al. Involvement of the osteoinductive factors, Tmem119 and BMP-2, and the ER stress response PERK-eIF2 $\alpha$-ATF4 pathway in the commitment of myoblastic into osteoblastic cells. Calcif Tissue Int 2014;94:454-64.

49. Ferreira E, Porter RM, Wehling N, et al. Inflammatory cytokines induce a unique mineralizing phenotype in mesenchymal stem cells derived from human bone marrow. J Biol Chem 2013;288:29494-505. 